\title{
EFFECT OF GRAVEL CONTENT ON SOIL SUCTION
}

\author{
Yaxu Liu ${ }^{1}$ *Ivan Gratchev², Somayeh Saeidi ${ }^{3}$ and Sameera Pitawala ${ }^{4}$ \\ ${ }^{1}$ Griffith School of Engineering, Griffith University, Australia; ${ }^{2,3,4}$ Griffith University, Australia \\ *Corresponding Author, Received: 2 Feb. 2017, Revised: 19 Feb. 2017, Accepted: 29 March 2017
}

\begin{abstract}
This paper seeks to a) investigate the effect of gravel on soil suction and b) establish whether results of standard suction tests using filter paper can accurately represent the value of suction that would be expected in the field. Eight natural soils with different soil gradation and plasticity were used to prepare two types of specimens: a) the "original" specimens (no change compared to the field soil), and b) "sieved" specimens - when the "original" soil was passed through a 2-mm sieve to meet the standard requirement. Comparisons of soil-water characteristics curves (SWCC) obtained for both types of specimens were made to better understand the effect of gravel content on total and matric suction. The obtained data indicated that the results of standard tests can significantly overestimate the soil suction. In particularly, it was found that as the gravel content increased from 4.8 to $19.6 \%$, the difference in suction between the "original" and "sieved" specimens increased to $14 \%$ (total suction) and almost 20\% (matric suction). The experimental data showed that the effect of gravel was more pronounced for low plasticity soils, compared to high and very high plasticity soils, in which the influence of gravel on suction was found to be insignificant. Although the "sieved" specimens tended to produce higher values of suction, this tendency might reverse for high and very high plasticity soils when their liquidity index (LI) became positive.
\end{abstract}

Keywords: Soil Suction, Laboratory Tests, Soil Gradation, Plasticity

\section{INTRODUCTION}

The process of suction plays an important role in the mechanics of unsaturated soils [1]. The available literature indicates that the suction phenomenon can affect the geotechnical properties of soil, including its shear strength [2], [3], which may result in natural disasters such as rainfallinduced landslides [4], [5]. It has long become common practice [6]-[9] to estimate the properties of unsaturated soils using soil-water characteristics curves (SWCC), which define the relationship between the soil suction and the gravimetric water (w) content (or either volumetric water content or the degree of saturation). Such SWCC can readily be obtained through a series of laboratory tests, or alternatively, they can be derived from empirical correlations established between soil suction and soil index properties [10], [11].

To measure soil suction in the laboratory, a few methods have been proposed in the past decades, among which the filter paper method appears to be a common choice due to its simplicity and low cost. Since its introduction by Gardner [12], this method has been actively developed [13]-[15], modified [16]-[18] and finally standardized by ASTM [19] to provide engineers and scientists with an effective tool to determine soil suction at relatively high ranges. According to the standard [19], the soil needs to be first passed through a $2 \mathrm{~mm}$ sieve to remove large-sized particles (including gravel) before a standard suction test can be performed.
However, this change in soil gradation may result in different values of soil suction compared to what would be expected if the "original" soil had been tested. It is logical to assume that for finegrained soils with a small amount of gravel, this discrepancy may be insignificant; however, for soils with a relatively high gravel content, this difference may be much higher and thus may have a more pronounced influence on soil suction. To clarify this issue, this study seeks to investigate the effect of gravel on suction characteristics of eight soils with different soil gradation and plasticity. A series of suction tests using filter paper were performed on specimens prepared from the "original" soil collected from the field, and specimens of the same soil but passed through a 2$\mathrm{mm}$ sieve to remove the gravel component. This paper presents and discusses the obtained results.

\section{SOILS USED}

Eight different soils from Queensland and New South Wales (Australia) were used in this study. These soils had different levels of plasticity ranging from low (CL) to very high (CV), according to the Casagrande's Plasticity chart [20]. The liquid limit (LL), plasticity index (PI) and grading properties are summarized in Table 1 . All eight soils contained a gravel component (Table 1) that varied from as low as $4.8 \%$ (Soil CV-1) to the highest of $19.6 \%$ (Soil CL-1). 
Table 1 Properties of the studied soils

\begin{tabular}{ccccccc}
\hline Name & $\begin{array}{c}\text { Gravel } \\
\%\end{array}$ & $\begin{array}{c}\text { Sand } \\
\%\end{array}$ & $\begin{array}{c}\text { Silt } \\
\%\end{array}$ & $\begin{array}{c}\text { Clay } \\
\%\end{array}$ & $\begin{array}{c}\text { LL } \\
\%\end{array}$ & $\begin{array}{c}\text { PI } \\
\%\end{array}$ \\
\hline ML-1 & 15.6 & 61.4 & 18.2 & 4.8 & 20.2 & 3.8 \\
CL-1 & 19.6 & 50.2 & 21.7 & 8.5 & 32.5 & 16.8 \\
CI-1 & 19.3 & 47.5 & 23.0 & 10.2 & 38.9 & 19.6 \\
CI-2 & 5.3 & 45.0 & 18.0 & 31.7 & 43.0 & 23.6 \\
CI-3 & 13.3 & 31.4 & 26.1 & 29.2 & 44.3 & 23.3 \\
CH-1 & 11.7 & 29.2 & 12.6 & 46.5 & 55.4 & 28.7 \\
CH-2 & 7.6 & 46.3 & 18.4 & 27.7 & 55.8 & 31.1 \\
CV-1 & 4.8 & 3.7 & 20.5 & 71.0 & 79.2 & 46.3 \\
\hline
\end{tabular}

\section{TESTING PROGRAM}

Each soil was divided into two parts: "original” and "sieved". The specimens prepared from the "original" soil had the same soil gradation (including gravel) that existed in the field. The specimens formed from the "sieved" soil were passed through a 2-mm sieve to satisfy the requirement of a standard suction test [19].

For each type of soil (either "original” or "sieved"), the specimen preparation technique and test procedure were as follows: dried soil was thoroughly mixed with distilled water to achieve the desired value of water content, then placed in plastic bags, and kept in a humidity-controlled room for at least $48 \mathrm{~h}$. For each soil, about 6 specimens were prepared with varying amounts of water content ranging from 5 to $40 \%$. The specimen was then compacted in an O-ring (42.5 $\mathrm{mm}$ - diameter, $24.5 \mathrm{~mm}$ - height) to achieve a dry density of $1.3 \mathrm{~g} / \mathrm{cm}^{3}$.

The soil suction test was performed using the standard Whatman No. 42 filter paper, following ASTM D5298 - 03 [19]. The filter paper was placed in the middle of the compacted specimen to measure the matric suction and on the top of the specimen (fine mesh was used to separate the filter paper from the soil) to measure the total suction. Each specimen was kept in an insulated container under constant temperature conditions $\left(20{ }^{\circ} \mathrm{C}\right)$ for 7 days. At the end of this time period, the weight of the filter paper was carefully measured using a balance with accuracy of $\pm 0.0001 \mathrm{~g}$, and the values of matric and total suction were calculated. The moisture content of the specimen was measured at the end of the test and used to draw SWCC.

\section{RESULTS AND DISCUSSION}

To demonstrate the effect of coarse-grained material on total suction of soil, two typical results of suction tests are given in Fig.1. Fig.1a presents SWCC obtained for the "original" and "sieved" specimens of Soil CI-2. It is evident from this figure that these two curves appear to be very similar having only a small, rather negligible difference between the corresponding values. However, in the case of Soil CL-1 (Fig. 1b), this difference becomes more pronounced, reaching as high as $12 \%$ (maximum difference) at a corresponding water content of about $13 \%$. It is noted that for both soils, the total suction in the "sieved" specimens was higher than the total suction measured in the "original" soil specimens.

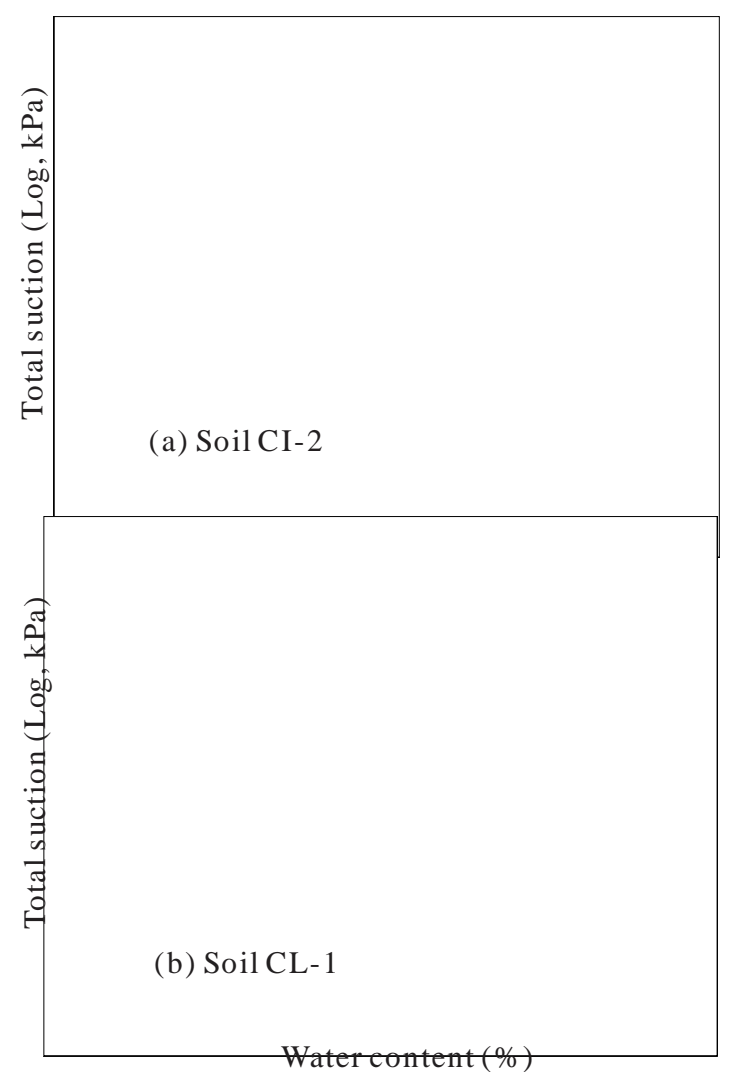

Fig.1 Results of suction tests obtained for Soil CI2 (a) and Soil CL-1 (b)

This finding seems to be in agreement with the published literature [6] which suggests that, compared to fine-grained soils, coarse-grained soils would typically have a lower water storage capacity (water content) provided the same value of soil suction. Fig.1 also indicates that results of standardized filter paper tests ("sieved" specimens) tend to produce higher values of soil suction compared to what would be expected in the field (“original” specimens).

To have a better understanding of the effect of gravel on soil suction, the obtained data are replotted in Fig.2 as the percentage of gravel component in the original soil against the maximum difference of SWCC between "sieved" and "original" soils for total (a) and matric (b) suction. The difference (D, \%) was calculated using Eq. (1). 
$D(\%)=\frac{\left(S_{S}-S_{o}\right)}{S_{o}} \cdot 100 \%$

where, $\mathrm{S}_{\mathrm{s}}$ - suction of "sieved" specimens, and $\mathrm{S}_{\mathrm{o}}$ - suction of "original" specimens.

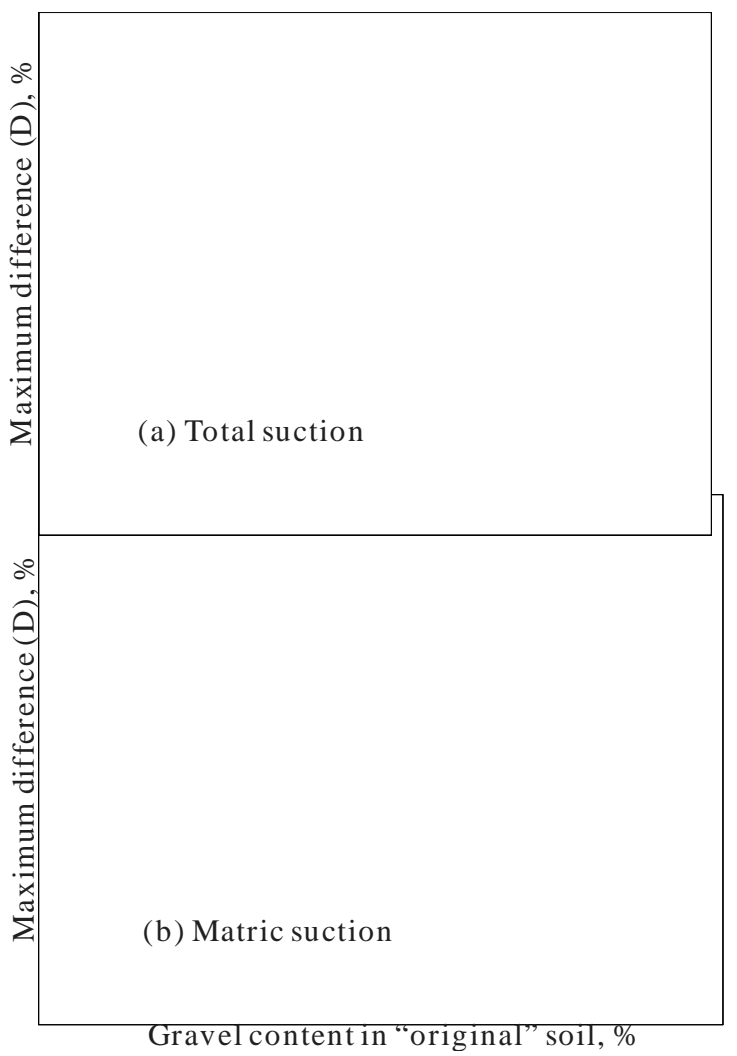

Fig.2 Results of suction tests plotted as the maximum difference (D, \%) between SWCC of "sieved" and "original" specimens against the gravel content: a) total suction, and b) matric suction

It is evident from Fig.2 that as the amount of gravel increases, the difference in suction values between "sieved" and "original" specimens also increases. For soils with a small amount of gravel (4-5\%), the difference only varies by about $5 \%$, suggesting that the effect of gravel on SWCC of such soils is rather limited. However, when the amount of gravel in the "original" soil reaches much higher values (15-19\%), the results from standard tests tend to overestimate the value of soil suction, compared to what would be expected in the "original" soil, by about $12-14 \%$ (total suction, Fig.2a) and 20\% (matric suction, Fig.2b). It is noted that this tendency exists for both total and matric suction, however, for the total suction, this correlation has a higher value of $\mathrm{R}^{2}(0.71)$.

It is interesting to analyze the difference (D) in suction in relation to soil plasticity because plasticity can provide an approximate estimation of soil suction [8]. Fig.3 presents the obtained results in terms of the maximum difference (D) against the liquid limit (LL) of soil. This plot indicates that $D$ decreases as LL increases, suggesting that the effect of gravel on soil suction tends to diminish as soil becomes more plastic. Also, the obtained data show that for soils of high or very high plasticity ( $L L \geq 50 \%$ ), the effect of gravel on suction is rather insignificant as D only varies from 5-7\%. However, at a relatively lower plasticity range $(\mathrm{L} L<40 \%)$, the difference (D) exceeds $10 \%$, and it can become as high as $19 \%$ at $L L=20.2 \%$ (Soil ML-1).

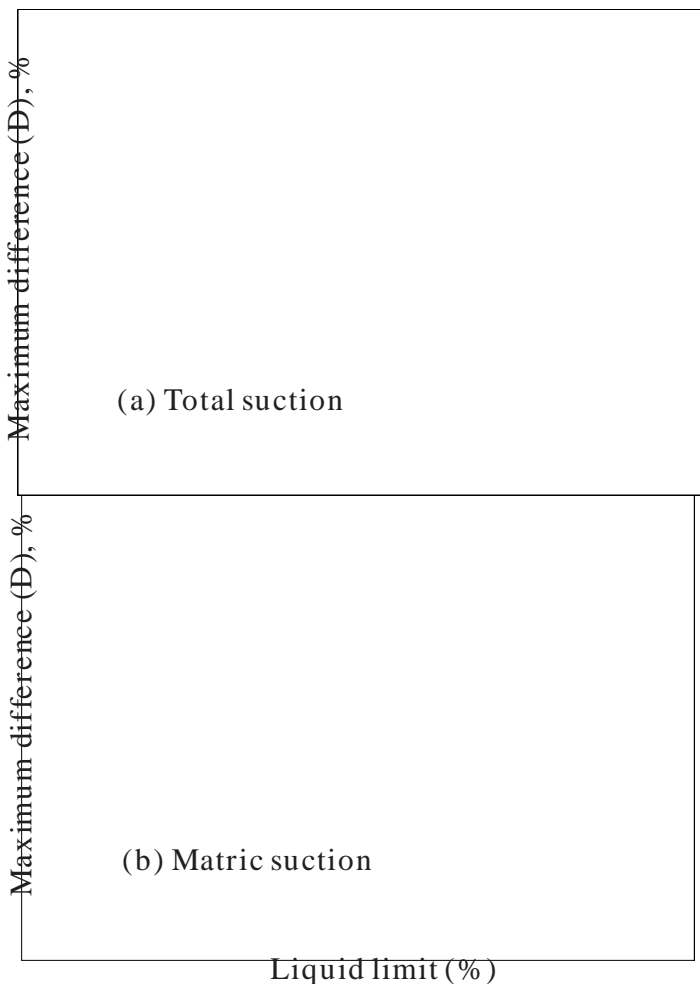

Fig.3 Results of suction tests plotted as the maximum difference (D, \%) between SWCC of "sieved" and "original" specimens against the liquid limit (LL) of soil: a) total suction, and b) matric suction

The experimental data revealed that the "sieved" specimens tend to produce higher values of soil suction compared to those obtained for the "original" specimens. This was mostly the case for the low and intermediate plasticity soils (Figs. 1 and 4a). However, for high and very high plasticity soils, there was the opposite tendency of higher values of soil suction produced by the "original" specimens at relatively higher water content. This seemed to correlate with the liquidity index (LI) of soils (CH-1 and $\mathrm{CH}-2)$ as shown in Figs. $4 \mathrm{~b}$ and c. It is evident from this figure that when LI becomes positive (that is, the water content of the specimen exceeds its plastic limit), the presence of gravel in the "original" specimens may lead to slightly higher values of soil suction. 


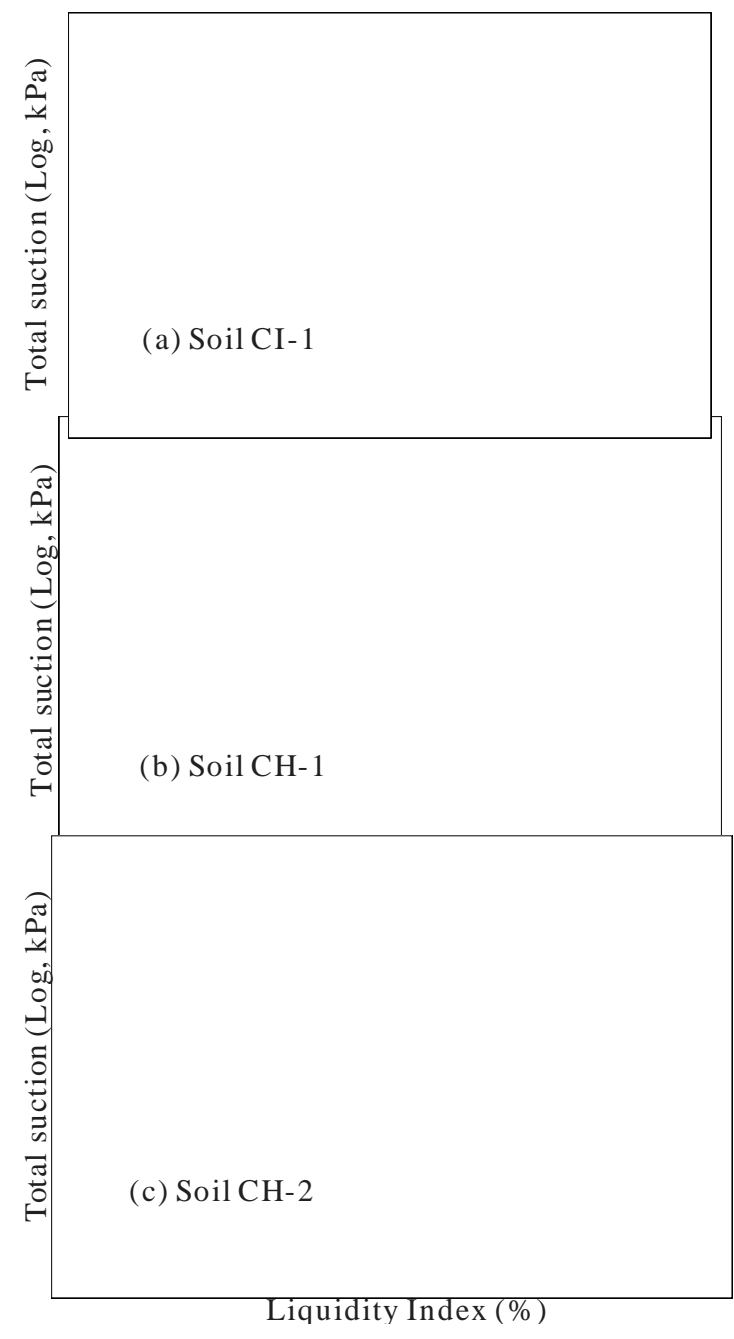

Fig.4 Results of suction tests plotted as the total suction against the liquidity index (LI) of three soils: a) Soil CI-1, b) Soil CH-1, and c) Soil CH-2

\section{CONCLUSION}

A series of suction tests on eight natural soils with different gradation and plasticity were performed to study the effect of gravel on soil suction and establish whether results from standard filter paper suction tests [19] on soil specimens passed through 2-mm sieve ("sieved" specimens) will accurately represent the value of suction that would be expected in the "original" soil from the field. Based on the obtained results, the following conclusions can be drawn:

- Standard suction tests performed on the "sieved" soil using filter paper tend to overestimate the suction value that would be expected in the "original" soil as such tests don't consider the effect of gravel.

- As the gravel content in the original soil increases, the difference in suction values measured for the same water content in "sieved" and "original" specimens also increases. At a low gravel content of about $5 \%$, this difference appears to be insignificant, however it can greatly increase when the gravel content reaches about $20 \%$.

- The effect of gravel on soil suction appears to be more pronounced in low plasticity soils $(\mathrm{LL}<35 \%)$ while it becomes rather negligible in high and very high plasticity soils.

- The "sieved" specimens tend to produce higher values of soil total suction; however, this tendency may reverse for high and very high plasticity soils as their liquidity index becomes positive.

\section{REFERENCES}

[1] Fredlund DG, and Rahardjo H, "Soil mechanics for unsaturated soils”, John Wiley \& Sons, 1993.

[2] Gallage C, and Uchimura T, "Direct shear testing on unsaturated silty soils to investigate the effects of drying and wetting on shear strength parameters at low suction”, Journal of Geotechnical and Geoenvironmental Engineering, Vol. 142(3), 2016, pp. 04015081.

[3] Nuntasarn R, and Wannakul V, "The Relationship between Soil Suction and the Maximum Unsaturated Undrained Shear Strengths of Compacted Khon Kaen Soil”, International Journal of Geomate, Vol. 2, No. 1, (SI. No. 3), 2012, pp. 166-170.

[4] Krahn J, Fredlund DG, and Klassen MJ, "Effect of soil suction on slope stability at Notch Hill”, Canadian Geotechnical Journal, Vol. 26(2), 1989, pp. 269-278.

[5] Springman SM, Jommi C, and Teysseire P, "Instabilities on moraine slopes induced by loss of suction: a case history”, Geotechnique, Vol. 53(1), 2003, pp. 3-10.

[6] Vanapalli SK, Fredlund DG, and Pufahl DE, "The influence of soil structure and stress history on the soil-water characteristics of a compacted till”, Geotechnique, Vol. 49(2), 1999, pp. 143-159.

[7] Simms PH, and Yanful EK, "Predicting soilwater curves of compacted plastic soils from measured pore-size distribution”, Geotechnique, Vol. 52(4), 2002, pp. 269-278.

[8] Marinho FAM, "Nature of soil-water characteristic curve for plastic soils”, Journal of Geotechnical and Geoenvironmental Engineering, Vol. 131(5), 2005, pp. 654-661.

[9] Agus SS, Schanz T, and Fredlund DG, "Measurements of suction versus water content for bentonite-sand mixtures", Canadian Geotechnical Journal, Vol. 47(5), 2010, pp. 583-594.

[10] Perera YY, Zapata CE, Houston WN, and Houston SL, "Prediction of the soil-water 
characteristic curve based on grain-sizedistribution and index properties", Advanced in Pavement Engineering, ASCE, 2005, pp. 112.

[11] Johari A, Habibagahi G, and Ghahramani A, "Prediction of soil-water characteristic curve using genetic programming”, Journal of Geotechnical and Geoenvironmental Engineering, Vol. 132(5), 2006, pp. 661-665.

[12] Gardner R, “A method of measuring the capillary tension of soil moisture over a wide moisture range”, Soil Science, Vol. 43(4), 1937, pp. 277-284.

[13] Fawcett RG, and Collis-George N, "A FilterPaper Method for Determining the Moisture Characteristics of Soil," Australian Journal of Experimental Agriculture and Animal Husbandry, Vol. 7, 1967, pp. 162-167.

[14] McQueen IS, and Miller RF, "Calibration and evaluation of a wide-range gravimetric method for measuring moisture stress”, Soil Science, Vol. 106(3), 1968, pp. 225-231.

[15] Al-Khafaf S, and Hanks RJ, "Evaluation of the filter paper method for estimating soil water potential”, Soil Science, Vol. 117(4), 1974, pp. 194-199.
[16] Hamblin A P, "Filter-paper method for routine measurement of field water potential”, Journal of Hydrology, Vol. 53(3), 1981, pp. 355-360.

[17] Chandler RJ, and Gutierrez CI, "The filterpaper method of suction measurement", Géotechnique, Vol. 36(2), 1986, pp. 265-268.

[18] Bulut R, Lytton RL, and Wray WK, "Soil suction measurements by filter paper”, In Expansive clay soils and vegetative influence on shallow foundations, 2001, pp. 243-261.

[19]ASTM D-5298 (2003). “Standard Test Method for Measurement of Soil Potential (Suction) Using Filter Paper1”, Annual Book of ASTM Standards, Vol 04.01.

[20] Casagrande A, "Research of Atterberg Limits of soils”, Public Roads, Vol. 13(8), pp. 121136.

Copyright (C) Int. J. of GEOMATE. All rights reserved, including the making of copies unless permission is obtained from the copyright proprietors. 